\title{
Effectiveness of Kangaroo Mother Care in Intubated Preterm Neonates 28 to 36 Weeks Gestational Age, Weighing 600 to 2000 Grams at Birth: A Randomized Controlled Trial
}

\author{
Shary May M. Baton, MD, Maria Esterlita T. Villanueva-Uy, MD, MSPH and Socorro De Leon-Mendoza, MD
}

Section of Nerwborn Medicine, Philippine General Hospital, University of the Philippines Manila

\begin{abstract}
Background. Kangaroo Mother Care (KMC) is the standard of care for stable low birth weight infants. Provision of $\mathrm{KMC}$ to intubated preterm infants may also be beneficial, but strong evidence is still lacking.
\end{abstract}

Objective. To determine the effectiveness of $\mathrm{KMC}$ in decreasing mortality among intubated preterm neonates.

Study Design. This is a non-blinded, parallel, non-inferiority randomized controlled trial.

Methodology. All intubated, preterm admissions, 28-36 weeks gestation, weighing 600-2000 grams, with respiratory distress were included. They were randomized to the intervention group who received KMC for 2-4 hours daily while intubated and the control group who received care inside an incubator. Participants' physiologic status before, during, and after the intervention - was recorded. The primary outcome was mortality. Secondary outcomes included comorbidities, days intubated, and hospital stay.

Results. There was a total of 32 patients. The risk of dying in the KMC group $(n=16)$ was significantly reduced by $78 \%$ (RR 0.22; $95 \% \mathrm{Cl} 0.06-0.87 \mathrm{p}=0.009$ ). The KMC patients were also less likely to have hypothermia, nosocomial pneumonia, NEC, and late-onset neonatal sepsis $(p<0.05)$. The KMC group had higher blood sugar levels (110 vs. $58, p=0.001$ ) and required fewer days of intubation (3.5 vs.1.5 days, $p<0.000$ ) compared to the control group. There was no difference in the duration of the hospital stay.

Conclusion. KMC is effective in decreasing mortality among intubated preterm neonates. Other comorbidities and days of intubation were also reduced.

Key Words: Kangaroo Mother Care, intubated preterm neonates, neonatal mortality, intubation days

\section{INTRODUCTION}

Poster presented in the $8^{\text {th }}$ Recent Advances in Neonatal Medicine Conference on October 8-10, 2017, at the Wurzburg, Germany.

Corresponding author: Shary May M. Baton, MD

Section of Newborn Medicine

Philippine General Hospital,

University of the Philippines Manila

Taft Avenue, Ermita, Manila 1000, Philippines

Email:sharymanuta@yahoo.com
The Kangaroo Mother Care (KMC) intervention has three essential components: 1) KMC position described as skin-to-skin contact between the preterm infant and the caregiver's chest in an upright, prone position, 2) breast milk/breastfeedings, and 3) early hospital discharge with outpatient follow-up care. It is now the standard of care for preterm or low birth weight (LBW) infants in many neonatal care units worldwide. In 1978, KMC was conceptualized in Bogotá, Colombia by Dr. Edgar Rey Sanabria and colleagues to address concerns of overcrowding and insufficient resources in the neonatal intensive care unit (NICU), which contribute to neonatal morbidity and mortality among LBW infants. From the 1990s to 


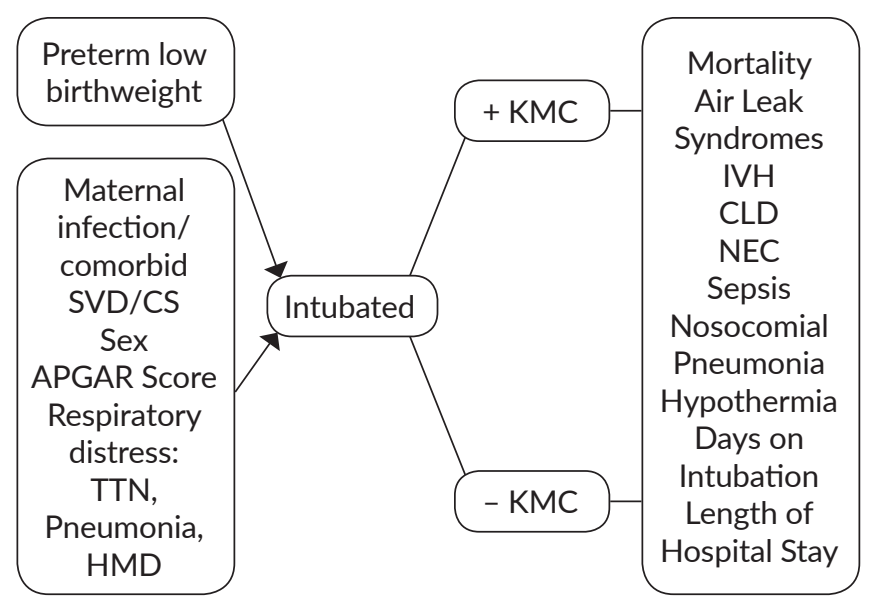

Figure 1. Concept Map of the Study.

the present, the research evidence supporting $\mathrm{KMC}$ as an intervention has been overwhelming at 1600 studies to date. ${ }^{1}$ Rigorous experiment and meta-analyses provide compelling evidence of the beneficial effects of KMC.

In the KMC position, the baby is placed prone, skinto-skin, in a vertical position between the mother's breasts. The baby is clothed only with a diaper, cap, and socks and secured with a blanket or tube blouse on the mother's chest. The mother is the primary source of warmth, nutrition, and stimulation for the baby. Any other person, however, can share the role of the KMC provider. Beneficial outcomes reported not only include decreased mortality and nosocomial infections. ${ }^{2-4}$ There is also improvement of physiologic stability such as prevention of hypothermia, reduced heart rate variability, and pain perception. -11 $^{5-1}$ Physiologic stability has been documented during interfacility transport in KMC. ${ }^{12}$ These studies on the physiologic effects of KMC have included very small ( $<1000$ grams), very preterm ( $<28$ weeks GA, $\leq 30$ weeks postmenstrual age when studied), and very sick infants, as well as more mature, older, and relatively stable preterm infants. ${ }^{13-16}$ These studies showed that the physiological effects of $\mathrm{KMC}$, for most variables, were better or similar to other premature infants under different forms of care. However, body temperature and weight gain significantly increased. A meta-analysis showed that the KMC position increases the uptake and duration of breastfeeding. Behavioral effects of $\mathrm{KMC}$ on the neonate showed rapid quiescence and improved sleeping patterns. ${ }^{17}$ The psychosocial impact of KMC include reduced stress, enhancement of mother-infant bonding, and positive effects on the family environment and the infant's cognitive development. ${ }^{18,19}$

After an extensive literature search, a research gap has been identified in the use of KMC among intubated preterm neonates. The volume of publications on $\mathrm{KMC}$ for intubated infants did not provide enough data to support or contradict caregivers' concerns about infants' physiological conditions during this intervention.

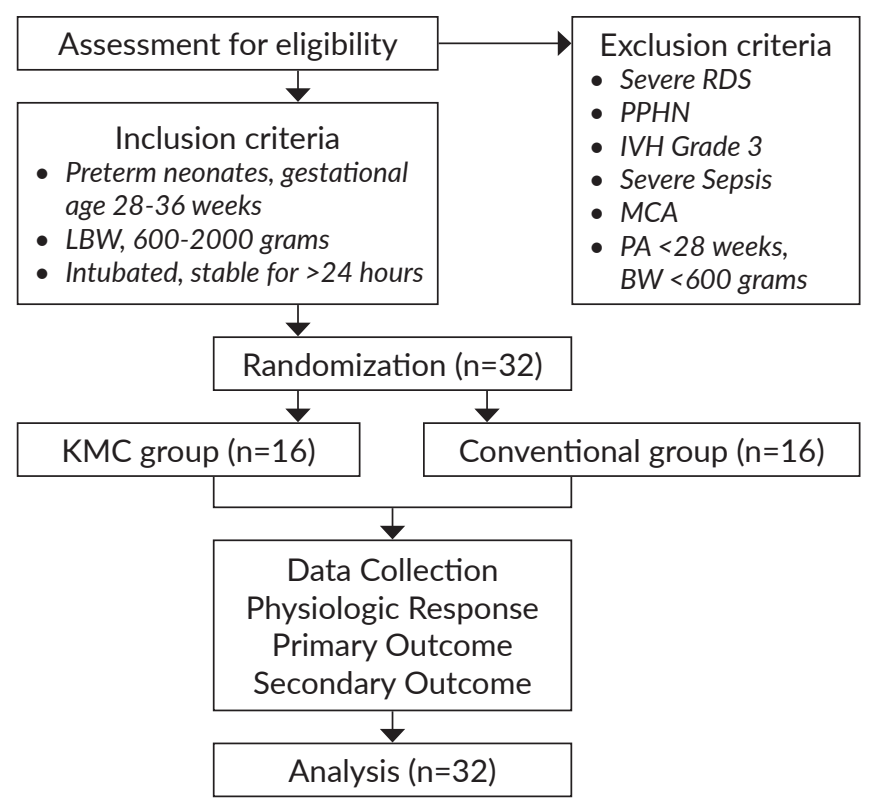

Figure 2. Flow Chart of the Study.

\section{Research Question}

Among intubated and ventilated preterm neonates 28 to 36 weeks gestational age with a weight between 600-2000 grams, will KMC effectively decrease mortality compared to conventional care?

\section{OBJECTIVE}

The main objective of this investigation is to determine the effectiveness of $\mathrm{KMC}$ in decreasing the mortality rate among intubated preterm neonates at 28 to 36 weeks gestational age and weight between 600 to 2000 grams compared to those on conventional care.

\section{METHODOLOGY}

Figures 1 and 2 illustrate the concept map and flow chart of the study, respectively.

\section{Study Design}

This study is a prospective, non-blinded, parallel, twoarm, non-inferiority randomized controlled trial conducted at the Philippine General Hospital (PGH) NICU.

\section{Study Population}

Eligible participants included all preterm neonates admitted at the NICU aged 28 to 36 weeks gestational age, weighing 600 to 2000 grams, requiring intubation and mechanical ventilation due to respiratory distress, but with a stable heart rate of 120 to $160, \mathrm{BP}$ within the normal range for weight and age of gestation, oxygen saturation > 90\% and no adverse respiratory events requiring emergent interventions during the previous 12 hours. 
Exclusion criteria include severe respiratory distress $\left(\mathrm{FiO}_{2}>50 \%\right)$, persistent pulmonary hypertension, intraventricular hemorrhage $\geq$ grade 3 , shock state as seen in severe sepsis, and significant congenital abnormalities especially facial and gastrointestinal anomalies. The study did not include preterm neonates with pediatric aging below 28 weeks and birth weight less than 600 grams.

All infants meeting the eligibility criteria were included in the study. Informed consent was obtained from the parents by the principal investigator, the research assistant, or both. Recruitment was at the NICU of the PGH once the baby was intubated and admitted at NICU III.

\section{Randomization}

After obtaining informed consent from the mother or father at the NICU, the infant was randomly assigned to either KMC or conventional care. Assignments were placed in opaque brown envelopes. The control group was provided conventional care inside incubators, while the treatment group received the KMC intervention. An analysis is an intention to treat.

\section{Intervention}

All parents of participants enrolled in the $\mathrm{KMC}$ group underwent KMC orientation. Fathers or mothers were the ones to provide $\mathrm{KMC}$ to their infants. They were instructed to hold their babies in a KMC position and were taught how to recognize danger signs such as apnea, cyanosis, and decreased movement. The research assistant (RA), who is a trained $\mathrm{KMC}$ nurse, assisted the principal investigator (PI) in the transfer of the intubated baby to the $\mathrm{KMC}$ position as well as monitored the babies during $\mathrm{KMC}$ sessions (Table 1). ${ }^{20}$

The parents providing $\mathrm{KMC}$ had their chest wiped dry with a clean cloth. Application of disinfectant on the parent's skin was avoided to allow the possibility of the infant's recognition of (familiar) maternal odors and initiation of colonization by paternal or maternal flora, which may enhance protection against healthcare-associated infections. ${ }^{21}$ After which, they did the prescribed hand washing and wore a KMC tube blouse with the prescribed NICU gown.

The parent was then correctly positioned on a comfortable, lounging chair which placed the parent's back in a slightly inclined position. The preterm neonate, clothed in diaper and cap, with stable vital signs and $\mathrm{O}_{2}$ saturations $\geq 90 \%$, was briefly disconnected from the ventilator by the RA while being gently placed by the investigator in a vertical, prone position against the father's or mother's chest. The RA immediately reconnected the tube to the ventilator while the investigator pulled up the tube blouse to cover the baby's back. The parents then wore the NICU gown with the opening on the front.

The infant was monitored for 10 to 15 minutes following transfer to assess any physiological disruption that might warrant immediate interruption of the intervention.
If physiological disruption persisted 15 minutes after transfer, the intervention (KMC position) would be discontinued, and a second attempt would be made the following day.

KMC was provided to all preterm neonates in the intervention group as soon as the infant demonstrated stable vital signs while on the ventilator. The infant and parent were intermittently kept on the $\mathrm{KMC}$ position for 2 to 4 hours daily until extubated. The KMC group recorded baseline heart rate, respiratory rate, blood pressure, and oxygen saturation by pulse oximetry and thermal values by digital thermometer 5 minutes before the intervention. At 15, 30, and 60 minutes during $\mathrm{KMC}$ position and every hour for a minimum of 2 hours, until the parent decided to return the baby to the incubator, at any time the neonate showed any signs of destabilization or both. Another set of vital signs were recorded 5 minutes before ending the intervention and 5 minutes after return to incubator.

\section{Control group}

The participants in the control group were provided care inside an incubator. Their heart rate, respiratory rate, blood pressure, and oxygen saturation by pulse oximetry and thermal values by digital thermometer were also recorded as per NICU protocol while intubated.

All the preterm neonates in both groups were managed similarly except for the KMC position in the intervention group. Since KMC is the standard of care for all preterm and LBW neonates in this facility, all neonates in both groups were enrolled in the KMC program as soon as they were extubated.

\section{Sample Size Estimation}

The proposed number of subjects was 74 preterm neonates at 37 per arm, based on a level of significance of $5 \%$, a power of $80 \%$, a margin of $20 \%$ to detect a $50 \%$ reduction in neonatal mortality in the $\mathrm{KMC}$ group, as noted from the reference article by Lawn, Mwansa-Kambafwile, Horta, et al. ${ }^{22}$ This also took into consideration a $10 \%$ dropout rate.

\section{Ethical Considerations}

The protocol was reviewed and approved by the University of the Philippines Manila Research Ethics Board.

\section{Data Analysis}

Descriptive statistics were used to summarize the clinical characteristics of the patients. Frequency and proportion were used for nominal variables, median and interquartile range (IQR) for ordinal variables, and mean and standard deviation (SD) for interval/ratio variables. Independent Sample T-test, Mann-Whitney U test, and Fisher's Exact/ Chi-square test were used to determine the difference of mean, median, and frequency between groups, respectively. We calculated relative risks with $95 \%$ confidence intervals (CI) for adverse events. Last-Observation-Carried-Forward 
Table 1. Safe Protocol Care on Transfer to KMC of Mechanically Ventilated Infants

\section{Safe Protocol for Kangaroo Care with Mechanically Ventilated Infants (KC-Vent) (Ludington-Hoe)}

JOGNN Principle and Practice, September/October $2003^{20}$

Kangaroo Care is skin-to-skin contact between a preterm infant and a parent, usually mother, chest-to-chest in an upright prone position. The infant is clad in a diaper and has a receiving blanket covering the infant's back. The optimal chair for experiencing kangaroo care is a recliner. Mechanically ventilated infants are intubated or receiving nasal CPAP or oropharyngeal CPAP via a ventilator. The physician will be contacted for approval to kangaroo the infant and confirmation of the infant's hemodynamic stability.

\section{Before transfer}

1. Record infant's baseline ventilator parameters (SIMV/IMV, PIP, PEEP, $\left.\mathrm{FiO}_{2}\right)$ and hemodynamic $\left(\mathrm{HR}, \mathrm{RR}, \mathrm{SaO}_{2}\right)$ and thermal values $(a x i l l a r y$ temperature). These measures should be carefully monitored during KC-Vent to ascertain the infant's tolerance of this intervention.

2. With the support of a second person, place the infant in a supine position. Note any significant changes in the infant or mechanical ventilator requirements.

3. Auscultate the infant's chest for quality of breath sounds, suction the endotracheal tube and change the infant's diaper as necessary.

4. Suction infant if necessary and drain the vent circuit of condensation. The water condensed in the ventilator tubing will be drained to decrease resistance and maintain flow (Bhutani \& Abbasi, 1992).

5. Assess the infant's response to the above actions. Wait up to 15 minutes to allow for physiological adaptation to the above ministrations. Adaptation is defined as all physiological parameters returning to baseline and staying there for 3 minutes. If adaptation has not occurred in 15 minutes, the infant is probably not stable enough to receive KC-Vent on that day.

6. Place a receiving blanket, folded in fourths, underneath the infant (or in the bed but easily accessible to the mother), so the mother picks up her infant by placing her hands underneath the blanket and moving infant and blanket simultaneously.

7. Position and prepare the chair to be used.

\section{Transfer from Incubator to KC-Vent}

1. Have two or three staff members assist the mother in the transfer of the infant.

2. Have the mother stand at the side of the incubator/warmer while one staff member gathers all the infant's lines on one side of the infant.

3. A second staff member is responsible for transferring and securing the ventilator tubing. (A third staff member may be needed to assist the mother.)

4. Disconnect the ventilator tubing from the ETT and have the mother lift her infant and place it prone on her chest in one movement.

5. Reconnect the ventilator tubing and have a mother or staff member quickly secure the receiving blanket across the infant's back (if not already placed when the mother picks up her infant as instructed in step 6 above).

6. Disconnect the ventilator tubing and move mother backward to recliner/chair, assisting her in sitting once she feels the recliner against her calf. Reconnect ventilator tubing to ETT.

7. Raise the footrest and reposition the infant, as needed, and make sure the infant is tucked in a slightly flexed or comfortable position underneath the blanket. If the infant is in the fully flexed position, monitor for respiratory compromise and reflux.

8. Drape the ETT circuit securely over the mother's shoulder (ensure adequate circuit tubing length has been provided).

9. Change the incubator/warmer setting to air control and set it at $33.0^{\circ} \mathrm{C}$ for the duration of $\mathrm{KC}$-Vent.

10. Monitor the infant's condition every 10 minutes during KC-Vent. Allow KC-Vent for a minimum of 1 full hour if the infant's condition remains stable.

\section{Transfer From KC-Vent Back to the Incubator}

1. Have one staff member assist the mother in moving to the front edge of the chair, a second staff member handle the lines, and a third staff member disconnect the ventilator tubing.

2. Assist the mother to a standing position, reconnect the ventilator tubing, and give the infant several ventilator breaths.

3. Disconnect the ventilator tubing and replace the infant in the incubator/warming table in one movement.

4. Reconnect the ventilator tubing and make sure all ventilator tubing is stabilized and all lines are placed securely within the incubator/ warming table.

5. Document infant's participation in and tolerance of KC-Vent.

Bhutani, V., \& Abbasi, S. (1992). Evaluation of pulmonary function in the neonate. In Polin \& Fox (Eds.), Fetal and neonatal physiology (Vol. 2, pp. 853871). Philadelphia: WB Saunders.

(LOCF) method was used for lost to follow-up patients. All valid data were included in the analysis. Missing variables were neither replaced nor estimated. Null hypotheses were rejected at $0.05 \alpha$-level of significance. STATA 12.0 was used for data analysis.

\section{RESULTS}

On interim analysis of the ethical review board, the recommendation was to stop recruitment already since the primary outcome analysis resulted in statistical significance. As such, there were 32 preterm infants enrolled, with 16 patients in each group. Post-hoc power analysis was $76.6 \%$.

Baseline characteristics between the KMC and the control group were similar in terms of maternal age and educational attainment, parity, mode of delivery, the average number of prenatal consultations, previous medications during pregnancy, and comorbidities except for the presence of maternal cough before delivery (Table 2).

Table 3 shows the clinical characteristics of preterm neonates. The two groups of neonates were similar in terms of sex, gestational age, birth anthropometrics, APGAR scores, type of respiratory disease, and baseline mechanical ventilator settings. 
Table 4 displays the average vital signs of the neonates during the intervention. Only two (2) of the neonates in the intervention group did not tolerate the KMC position at first try. However, the second attempt on the following day and the rest of the study period were all without incident. On observation of the mean values of the vital signs, the heart rate and respiratory rate remain the same from baseline to 5 minutes until the end of the $\mathrm{KMC}$. There was a slight increase in heart rate and respiratory rate 5 minutes after the infant was returned to the incubator. Notably, the temperature of the infants tends to increase (still within normal range) until the end of the KMC session and once returned to the incubator. Oxygen saturations also started to increase after one hour of KMC until the end of the session. Systolic and diastolic blood pressure also were increasing while on KMC but were still within the normal range.

This study showed that intubated neonates who received KMC were significantly less likely to have inhospital mortality ( $\mathrm{RR}=0.22(95 \% \mathrm{CI} 0.06$ to $0.87, \mathrm{p}$ $=0.009)$. This indicated a $78 \%$ reduction in the risk of dying in the KMC group compared to controls. Similarly, patients in the KMC group were significantly less likely to have hypothermia $(\mathrm{RR}=0.21)$, nosocomial pneumonia $(\mathrm{RR}=0.36)$, NEC $\mathrm{RR}=0.30)$, and late-onset sepsis $(\mathrm{RR}=$ 0.36). The conventional care group's median random blood sugar level was significantly lower than that of the KMC group (58 versus $110, p=0.001$ ). There were no significant differences in the incidence of air leak syndromes and IVH between the two groups (Table 5).

Table 6 shows that neonates in the KMC group had a lower median number of intubated days than the conventional care group ( 1.5 versus 3.5 days, $\mathrm{p}<0.000$ ). None of the KMC patients had accidental extubations. There was no significant difference in length of hospital stay. After the study period (once the infant is extubated), all parents of either intervention or control group were encouraged to provide KMC to their infants. Eighty-seven percent of the $\mathrm{KMC}$ parents continued to provide KMC to their infants compared with $50 \%$ of the control. However, this did not reach statistical significance.

\section{DISCUSSION}

This is the first randomized controlled trial providing $\mathrm{KMC}$ to intubated infants and positive pressure ventilation. In this study, physiologic parameters tend to improve while on $\mathrm{KMC}$, especially for the temperature and the oxygen saturation. In two case studies by Drosten-Brooks, the intubated infants placed on $\mathrm{KMC}$ exhibited increased quiet sleep and decreased oxygen requirements during KMC sessions. ${ }^{23}$ In the study by Gale, Franck, and Lund (1993), skin-to-skin holding of 25 intubated infants in the NICU

Table 2. Demographic and Clinical Characteristics of Mothers of Intubated Preterm Neonates Born 28 to 36 weeks Admitted at the Philippine General Hospital $(n=32)$

\begin{tabular}{|c|c|c|c|}
\hline \multirow{3}{*}{ Maternal Age (Years) } & Kangaroo care $(n=16)$ & Conventional care $(\mathrm{n}=16)$ & \multirow{3}{*}{$\begin{array}{l}\text { P-value } \\
0.336^{\ddagger}\end{array}$} \\
\hline & \multicolumn{2}{|c|}{ Frequency (\%); Mean \pm SD; Median (Range) } & \\
\hline & $31.75 \pm 7.54$ & $29.19 \pm 7.30$ & \\
\hline $\begin{array}{l}\text { Educational attainment } \\
\text { High school } \\
\text { College } \\
\text { N/A }\end{array}$ & $\begin{array}{c}6(37.5) \\
8(50) \\
2(12.5)\end{array}$ & $\begin{array}{l}9(56.25) \\
6(37.5) \\
1(6.25)\end{array}$ & 0.587 \\
\hline $\begin{array}{l}\text { Parity } \\
\text { Primiparous } \\
\text { Multiparous } \\
\text { Grand multipara } \\
\end{array}$ & $\begin{array}{c}3(18.75) \\
8(50) \\
5(31.25) \\
\end{array}$ & $\begin{array}{c}8(50) \\
7(43.75) \\
1(6.25) \\
\end{array}$ & 0.083 \\
\hline $\begin{array}{l}\text { Mode of delivery } \\
\text { Spontaneous vaginal delivery } \\
\text { Cesarean section }\end{array}$ & $\begin{array}{c}5(31.25) \\
11(68.75)\end{array}$ & $\begin{array}{c}5(31.25) \\
11(68.75)\end{array}$ & $1.000^{*}$ \\
\hline Number of prenatal check-ups & $4.85 \pm 2.19$ & $5 \pm 2.41$ & $0.871^{\ddagger}$ \\
\hline $\begin{array}{l}\text { Comorbidities** } \\
\text { Hypertension } \\
\text { Urinary tract infection } \\
\text { Premature rupture of membranes } \\
\text { Others } \\
\text { Diabetes } \\
\text { Cough }\end{array}$ & $\begin{array}{c}7(43.75) \\
5(31.25) \\
5(31.25) \\
3(18.75) \\
0 \\
0\end{array}$ & $\begin{array}{c}7(43.75) \\
6(37.5) \\
7(43.75) \\
3(18.75) \\
1(6.25) \\
5(31.25)\end{array}$ & $\begin{array}{l}1.000^{*} \\
0.710^{*} \\
0.465^{*} \\
1.000 \\
1.000 \\
0.043\end{array}$ \\
\hline Receiving antibiotic treatment & $2(12.50)$ & $4(25)$ & 0.645 \\
\hline Receiving steroids treatment & $11(68.75)$ & $13(81.25)$ & 0.685 \\
\hline Dose of steroids $(n=24)$ & 1 (1 to 4$)$ & $1(1$ to 4$)$ & $0.420^{+}$ \\
\hline
\end{tabular}

Statistical Tests Used: Fisher's Exact test; ${ }^{*}$ - Chi-Square test; ${ }^{\ddagger}$ - Independent Sample T-test; ${ }^{\dagger}$ - Mann-Whitney U test ** - Multiple Responses 
Table 3. Clinical Characteristics of Intubated Preterm Neonates Born 28 to 36 weeks Admitted at the Philippine General Hospital ( $n=32)$

\begin{tabular}{|c|c|c|c|}
\hline & Kangaroo care $(n=16)$ & Conventional care $(n=16)$ & D \\
\hline & Frequency (\%); Me & SD; Median (Range) & -value \\
\hline $\begin{array}{l}\text { Sex } \\
\text { Male } \\
\text { Female }\end{array}$ & $\begin{array}{l}8(50) \\
8(50)\end{array}$ & $\begin{array}{c}6(36.5) \\
10(62.5)\end{array}$ & $0.476^{*}$ \\
\hline Gestational Age (weeks) & $30.63 \pm 2.16$ & $30.13 \pm 2.03$ & $0.505^{\ddagger}$ \\
\hline $\begin{array}{l}\text { Gestational Age } \\
\text { Appropriate for Gestational Age } \\
\text { Small for Gestational Age } \\
\text { Large for Gestational Age }\end{array}$ & $\begin{array}{l}14(87.5) \\
1(6.25) \\
1(6.25) \\
\end{array}$ & $\begin{array}{c}14(87.5) \\
2(12.5) \\
0\end{array}$ & 1.000 \\
\hline Birthweight (grams) & $1441.88 \pm 361.56$ & $1262.81 \pm 345.24$ & $0.162^{\ddagger}$ \\
\hline Birth Length $(\mathrm{cm})$ & $38.69 \pm 4.21$ & $38.25 \pm 3.64$ & $0.755^{\ddagger}$ \\
\hline $\begin{array}{l}\text { APGAR score } \\
1 \text { minute } \\
5 \text { minutes }\end{array}$ & $\begin{array}{l}4.69 \pm 2.02 \\
7.31 \pm 1.66 \\
\end{array}$ & $\begin{array}{l}5.06 \pm 2.21 \\
7.38 \pm 1.41 \\
\end{array}$ & $\begin{array}{l}0.620^{\ddagger} \\
0.909^{\ddagger}\end{array}$ \\
\hline $\begin{array}{l}\text { Respiratory Disease } \\
\text { Hyaline Membrane Disease } \\
\text { Transient Tachypnea of the Newborn } \\
\text { Neonatal Pneumonia }\end{array}$ & $\begin{array}{l}7(43.75) \\
6(37.5) \\
3(18.75) \\
\end{array}$ & $\begin{array}{c}10(62.5) \\
2(12.5) \\
4(25)\end{array}$ & 0.326 \\
\hline $\begin{array}{l}\text { Mechanical Ventilator Setting } \\
\mathrm{FIO}_{2} \\
\mathrm{PIP} \\
\text { Positive End-Expiratory Pressure } \\
\text { Respiratory Rate } \\
\text { iTime }\end{array}$ & $\begin{array}{c}32.31 \pm 8.17 \\
16(14 \text { to } 20) \\
5(4 \text { to } 6) \\
33.5 \pm 10.99 \\
0.4(0 \text { to } 0.4) \\
\end{array}$ & $\begin{array}{c}33.06 \pm 8.45 \\
16(12 \text { to } 30) \\
5(4 \text { to } 7) \\
35.71 \pm 12.26 \\
0.4(0.3 \text { to } 0.4) \\
\end{array}$ & $\begin{array}{l}0.800^{\ddagger} \\
0.079^{\S} \\
0.862^{\S} \\
0.596^{\ddagger} \\
0.279^{\S}\end{array}$ \\
\hline
\end{tabular}

Statistical Tests Used: Fisher's Exact test; ${ }^{*}$ - Chi-Square test; ${ }^{*}$ - Independent Sample T-test; ${ }^{\S}$ - Mann-Whitney U test

Table 4. Physiological Characteristics of the Neonates in Kangaroo Care $(n=16)$

\begin{tabular}{|c|c|c|c|c|c|c|c|c|}
\hline & $\begin{array}{c}5 \text { mins } \\
\text { before start }\end{array}$ & $\begin{array}{c}15 \text { mins } \\
\text { during }\end{array}$ & $\begin{array}{c}30 \text { mins } \\
\text { during }\end{array}$ & $\begin{array}{c}60 \text { mins } \\
\text { during }\end{array}$ & $2^{\text {nd }}$ hour & $3^{\text {rd }}$ hour & $\begin{array}{l}5 \text { mins prior } \\
\text { to end }\end{array}$ & $\begin{array}{l}5 \text { mins back } \\
\text { in incubator }\end{array}$ \\
\hline & \multicolumn{8}{|c|}{ Mean \pm SD; Median (Range) } \\
\hline$H R$ & $144.13 \pm 17.66$ & $141.69 \pm 15.97$ & $141 \pm 14.54$ & $141.81 \pm 14.47$ & $142.38 \pm 14.10$ & $141.81 \pm 13.75$ & $140.69 \pm 12.86$ & $148.13 \pm 10.75$ \\
\hline$R R$ & $44.5(38,62)$ & $46(40,60)$ & $43(40,58)$ & $42(38,60)$ & $42(36,60)$ & $41.5(36,60)$ & $42(38,60)$ & $52(43,65)$ \\
\hline Temp & $36.34 \pm 0.38$ & $36.63 \pm 0.49$ & $36.73 \pm 0.51$ & $36.88 \pm 0.39$ & $36.95 \pm 0.37$ & $36.98 \pm 0.40$ & $36.97 \pm 0.38$ & $36.85 \pm 0.32$ \\
\hline $\mathrm{O}_{2}$ Sat & $96(83,99)$ & $96.5(85,100)$ & $96(88,99)$ & $97(89,100)$ & $97(90,99)$ & $97.5(90,99)$ & $98(92,99)$ & $96(90,98)$ \\
\hline \multicolumn{9}{|l|}{$B P$} \\
\hline Systolic & $61.5 \pm 9.71$ & $64.19 \pm 10.60$ & $64.88 \pm 8.88$ & $66.81 \pm 8.28$ & $66.06 \pm 7.29$ & $67.06 \pm 7.44$ & $67.06 \pm 6.60$ & $63.38 \pm 6.06$ \\
\hline Diastolic & $35.81 \pm 7.45$ & $38.31 \pm 7.96$ & $39.25 \pm 7.66$ & $39.63 \pm 6.12$ & $38.31 \pm 8.68$ & $39.44 \pm 6.58$ & $40.13 \pm 4.87$ & $36.81 \pm 5.38$ \\
\hline
\end{tabular}

weighing 0.7 to $1.3 \mathrm{~kg}, 28-33$ weeks postconceptional age with a diagnosis of respiratory distress syndrome at the time of study and received ad libitum amounts (15 minutes to $>20$ hours over one or more sessions) of KMC, also showed better thermoregulation during $\mathrm{KMC}$ compared when they were inside an incubator. ${ }^{24}$ In addition, once an infant settled on the mother's chest, their oxygen saturation rose, and they tended to have 15-20 minutes of quiet comfort before "becoming wriggly." Although one accidental extubation occurred in the study of Gale, this infant was returned to the incubator and was re-intubated without complications. In another observational study by Azevedo, KMC for preterm neonates on mechanical ventilation were assessed for 90 minutes (15 min before, $60 \mathrm{~min}$ during $\mathrm{KMC}$, and
15 min after). ${ }^{3}$ These periods demonstrated that the heart rate, oxygen saturation $\left(\mathrm{SpO}_{2}\right)$, axillary temperature, and mean arterial blood pressure were more stable during $\mathrm{KMC}$ $(p<0.05)$. In another observational study by Carbasse of 141 SSC sessions in 96 preterm infants (18\% - intubated, 52\% nasal CPAP, 30\% - on room air), there was increased oxygen saturation $(\mathrm{P}<0.005)$; decreased $\mathrm{FiO}_{2}$ requirement $(\mathrm{P}=0.043)$; greater heart rate stability $(\mathrm{P}<0.001) .{ }^{25}$ During transfer into SSC, mean axillary temperature dropped moderately but transiently $(\mathrm{P}<0.05)$. No extubations occurred. Apnea and bradycardia requiring minor intervention occurred in $13 \%$ of SSC sessions, but none required SSC termination. Carbasse concluded that SSC was safe and beneficial for clinically stable preterm infants, including those ventilated 
Table 5. Mortality and Other Neonatal Complications of Intubated Preterm Neonates Born 28 to 36 weeks from Admission to Discharge $(n=32)$

\begin{tabular}{|c|c|c|c|c|}
\hline & Kangaroo care $(n=16)$ & Conventional care $(n=16)$ & \multirow{2}{*}{$\begin{array}{l}\text { Relative Risk* } \\
\text { (95\% CI) }\end{array}$} & \multirow{2}{*}{ P-Value } \\
\hline & \multicolumn{2}{|c|}{ No. (\%) } & & \\
\hline Mortality & $2(12.5)$ & $9(56.25)$ & $0.22(0.06,0.87)$ & 0.009 \\
\hline Air Leak Syndromes & $1(6.25)$ & $3(18.75)$ & $0.33(0.04,2.87)$ & 0.285 \\
\hline Intraventricular Hemorrhage & $1(6.25)$ & $1(6.25)$ & $1(0.07,14.64)$ & 1.000 \\
\hline Chronic Lung Disease & $1(6.25)$ & 0 & - & 0.310 \\
\hline Hypothermia & $3(18.75)$ & $14(87.5)$ & $0.21(0.08,0.60)$ & $<0.000$ \\
\hline Nosocomial Pneumonia & $4(25)$ & $11(68.75)$ & $0.36(0.15,0.90)$ & 0.013 \\
\hline Necrotizing Enterocolitis & $3(18.75)$ & $10(62.5)$ & $0.3(0.10,0.89)$ & 0.012 \\
\hline Late-Onset Neonatal Sepsis & $5(31.25)$ & $14(87.5)$ & $0.36(0.17,0.76)$ & 0.001 \\
\hline Random Blood Sugar [Mean Range] & $110(70-200)$ & $58.34(50-150)$ & & $0.001^{\S}$ \\
\hline
\end{tabular}

${ }^{*}$ For nominal variables only. Statistical Tests Used: ${ }^{\S}$ - Independent Sample T-test; Chi-Square test

Table 6. Clinical Outcomes on Intubation and Hospital Stay of Intubated Preterm Neonates Born 28 to 36 weeks Admitted at the Philippine General Hospital $(n=32)$

\begin{tabular}{lccc} 
& Kangaroo care $(\mathbf{n = 1 6 )}$ & Conventional Care $(\mathbf{n = 1 6 )}$ & \multirow{2}{*}{ P-Value } \\
\cline { 2 - 3 } Days on Intubation & \multicolumn{1}{c}{ Frequency (\%); Median (Min, Max) } & $<0.000^{*}$ \\
\hline Accidental Extubation & $1.5(1,3)$ & $3.5(2,12)$ & - \\
\hline Length of Hospital Stay (day) & $0(0)$ & $0(0)$ & $0.474^{*}$ \\
\hline Growth & $21(5,93)$ & $17.5(3,145)$ & $0.158^{\S}$ \\
Discharge weight of survivors (gms) & $1554.29 \pm 151.76$ & $1432.14 \pm 228.73$ & $0.581^{\S}$ \\
Discharge length of survivors (cm) & $39.43 \pm 3.88$ & $38.43 \pm 3.78$ & $0.067^{\S}$ \\
\hline Compliance to KMC Post-Extubation & & & \\
Yes & $14(87.5)$ & $8(50)$ & \\
No & 0 & $2(12.50)$ & $6(37.5)$ \\
N/A & $2(12.5)$ & & \\
\hline
\end{tabular}

${ }^{*}$ For nominal variables only. Statistical Tests Used: * - Mann-Whitney U test; $\S$ - Fisher's exact test

and those $<1000 \mathrm{gm}$. The investigators proposed that "earlier and longer" (the practice of SSC) could improve neurodevelopmental outcomes. These observational studies and our study showed safety in providing KMC to intubated babies and showed evidence of a much calmer infant based on the physiologic parameters.

In this study, no accidental extubation occurred during the intervention period or KMC sessions using the described transfer method. Whereas Ludington-Hoe, in 2003, described a detailed protocol on the "standing transfer" for the provision of $\mathrm{KMC}$ while being mechanically ventilated, this study found the "sitting transfer" safer and more efficient. ${ }^{20}$ Only two participants did not tolerate the initial KMC position, but subsequent attempts were well tolerated. All other intubated babies receiving $\mathrm{KMC}$ remained physiologically stable during the initial positioning and the entire $\mathrm{KMC}$ sessions, lasting 2-4 hours daily. The safety of KMC among intubated preterm neonats was reinforced in this study.

Provision of KMC to unstable, ventilated infants or both remains controversial. In a case report by Swinth, a 33-weekgestation infant with mild respiratory distress at birth, eventually requiring intubation and mechanical ventilation, placing the preterm neonate in a KMC position was shown to assist in, rather than retard, recovery from respiratory distress.26 In this RCT, the infants also seem to recover faster, as demonstrated by the significantly shorter intubation days among KMC infants. Better physiologic parameters may indicate decreased energy utilization so that energy is used for growth and recovery.

This study demonstrated the effectiveness of $\mathrm{KMC}$ in decreasing mortality among intubated preterm neonates. The risk of dying in intubated preterm neonates in the KMC group was reduced by $78 \%$ compared with the control group. Co-morbid conditions such as hypothermia, nosocomial pneumonia, necrotizing enterocolitis, and late-onset sepsis were significantly less in the KMC group. In the metaanalysis of Conde-Agudelo5, there was also a significant reduction in comorbidities. The decline in sepsis, a leading cause of neonatal mortality, may have led to significantly lower mortality among the KMC group. Data gathered on these subjects was from the time of admission of these neonates to NICU III up to the time of discharge.

The median random blood sugar levels were also significantly higher (within the normal range) in the 
KMC group than those in the control group. Although the mechanism of sugar control has not been well elucidated, Chiruvolu proposes the following reasons. ${ }^{27}$ First is that better thermoregulation and brown fat stabilization lead to the prevention of glycogen store depletion. Second, KMC decreases neurosteroids indicating less stress which leads to better energy conservation and blood glucose stabilization. Lastly, KMC is associated with higher colostrum output which has also been shown to stabilize glucose levels.

In the meta-analysis of Conde-Agudelo, KMC has been found to have a dose-response effect in their benefits. ${ }^{5}$ The earlier and the longer duration/day KMC is provided, the lower the neonatal mortality rates were seen. In this study, an institution of KMC, even while the infant was still intubated, led to higher compliance after the study period. Though not statistically significant, the continuation of $\mathrm{KMC}$ provision among the $\mathrm{KMC}$ group may have led to lower comorbidities among these infants. However, growth rates and hospital stay remained the same. Further studies can further elucidate the effects of $\mathrm{KMC}$ compliance while in the hospital and after discharge.

\section{CONCLUSION}

KMC can be safely provided to intubated preterm neonates. Furthermore, KMC significantly reduced mortality, other comorbidities, and duration of intubation among these infants.

\section{Statement of Authorship}

All authors participated in the data collection and analysis and approved the final version submitted.

\section{Author Disclosure}

All authors declared no conflicts of interest.

\section{Funding Source}

This study was funded by the Kangaroo Mother Care Foundation Philippines, Inc.

\section{REFERENCES}

1. Luddington-Hoe SM. New Perspectives on Kangaroo Care [Commentary]. eNeonatal Review. 2015; 10(5).

2. Abouelfettoh AM, Ludington-Hoe SM. Preterm Twins Cardiorespiratory, Thermal and Maternal Breast Temperature Responses to Shared Kangaroo Care. Int J Nurs Midwifery. 2012;4(6):76-83.

3. Azevedo VMG, Xavier CC, Gontijo Fde. Safety of Mother Care in Intubated Neonates under 1500 g. J Trop Pediatr. 2012;58(1):38-42.

4. Cong X, Cusson RM, Walsh S, Hussain N, Ludington-Hoe SM, Zhang, D. Effects of Skin-to-skin Contact on Autonomic Pain Responses in Preterm Infants. J Pain. 2012; 13(7),636-45.

5. Conde-Agudelo A, Belizán J M, Diaz-Rossello J. Kangaroo Mother Care to Reduce Morbidity and Mortality in Low Birthweight Infants. Cochrane Database Syst Rev. 2011; 3(3).

6. Lawn JE, Davidge R, Paul VK, von Xylander S, de Graft Johnson J, Costello A, et al. Born too Soon: Care for the Preterm Baby. Reprod Health. 2013;10(supp):1-19.
7. Moore ER, Anderson GC, Bergman N, DowswellT. Early Skin-to-skin Contact for Mothers and Their Healthy Newborn Infants. Cochrane Database Syst Rev. 2012.16 May 2012. DOI: 10.1002/14651858. CD003519.pub.

8. Chitty H, Wyllie J. Importance of Maintaining the Newly Born Temperature in the Normal Range from Delivery to Admission. Semin Fetal Neonatal Med. 2013;18(6):362-8.

9. Ludington-Hoe SM, Nguyen N, Swinth JY, Satyshur RD. Kangaroo Care Compared to Incubators in Maintaining Body Warmth in Preterm Infants. Biol Res Nurs. 2000; Jul 2(1):60-73.

10. Johnston C, Stevens B, Craig K D, Grunau RV. Developmental Changes in Pain Expression in Premature, Full-term, Two-and fourmonth-old Infants. Pain. 1993;52(2): 201-8.

11. Funk RS, Brown JT, Abdel-Rahman SM. Pediatric Pharmacokinetics: Human Development and Drug Disposition. Pediatr Clin N Am. 2012;59(5):1001-1016.

12. Sontheimer D, Fischer CB, Buch KE. Kangaroo Transport Instead of Incubator Transport. Pediatrics. 2004;113(4):920-3.

13. Ludington-Hoe SM. Kangaroo Care as a Neonatal Therapy. Newborn Infant Nurs Rev. 2013;13(2):73-5.

14. Ludington-Hoe SM. Thirty Years of Kangaroo Care Science and Practice. Neonatal Network: J Neonatal Nurs. 2011;30(5):357-62.

15. Bergman NJ, Linley LL, Fawcus SR. Randomized Controlled Trial of Skin-to-skin Contact from Birth versus Conventional Incubator for Physiological Stabilization in 1200-to 2199- Gram Newborns. Acta Paediatr. 2004;93(6):779-85.

16. Hedberg Nyqvist K, Heinemann AB. Kangaroo Mother Care: Optimal Support of Preterm Infants' Transition to Extra-Uterine Life in the High Tech NICU Environment. Curr Women's Health Rev. 2011;7(3):278-87.

17. Feldman R, Weller A, Sirota L, Eidelman AI. Skin-To-Skin Contact (Kangaroo Care) Promotes Self-Regulation in Premature Infants: Sleep-Wake Cyclicity, Arousal Modulation, and Sustained Exploration. Dev Psychol. 2002; 38(2):194-207.

18. Feldman R, Rosenthal Z, Eidelman AI. Maternal-preterm Skin-toskin Contact Enhances Child Physiologic Organization and Cognitive Control Across the First 10 Years of Life. Biol Psychiatry. 2014;75(1): 56-64.

19. Blomquist YT, Nygvist KH. Swedish Mothers' Experience of Continuous Kangaroo Mother Care. J Clin Nurs. 2011 May; 20(910):1472-80.

20. Ludington-Hoe SM, Ferreira C, Swinth J, Ceccardi JJ. Safe Criteria and Procedure for Kangaroo Care with Intubated Preterm Infants. J Obstet Gynecol Neonatal Nurs. 2003 Sep-Oct;32(5):579-88.

21. Lamy Filho F, de Sousa S, Freitas I, Lamy Z, Simões V, da Silva A, et al. Effect of Maternal Skin-to-skin Contact on Decolonization of Methicillin-Oxacillin-Resistant Staphylococcus in Neonatal Intensive Care Units: A Randomized Controlled Trial. BMC Pregnancy Childbirth. 2015 Mar 19;15:63. doi: 10.1186/s12884-015-0496-1.

22. Lawn J, Mwansa-Kambafwile J, Horta B, Barros F, Cousens S. 'Kangaroo Mother Care' to Prevent Neonatal Deaths due to Preterm Birth Complications. Int J Epidemiol. 2010;39:i144-i54.

23. Drosten-Brooks, F. Kangaroo Care: Skin-to-skin Contact in the NICU. MCN Am J Matern Child Nurs. 1993; 18(5):250-3.

24. Gale G, Franck L, Lund C. Skin-to-skin (Kangaroo) Holding of the Intubated Premature Infant. Neonatal Netw. 1993 Sep;12(6):49-57.

25. Carbasse A, Kracher S, Hausser M, Langlet C, Escande B, Donato L, et al. Safety and Effectiveness of Skin-to-skin Contact in the NICU to Support Neurodevelopment in Vulnerable Preterm Infants. J Perinat Neonatal Nurs. 2013;27(3):255-62.

26. Swinth JY, Anderson GC, Hadeed AJ. Kangaroo (Skin-to-skin) Care with a Preterm Infant Before, During, and After Mechanical Ventilation. Neonatal Netw. 2003 Nov-Dec;22(6):33-8.

27. Chiruvolu A, Miklis KK, Stanzo KC, Petrey B, Groves CG, McCord $\mathrm{K}$, et al. Effects of Skin-to-Skin Care on Late Preterm and Term Infants At-Risk for Neonatal Hypoglycemia. Pediatr Qual Saf. 2017 Jun 20;2(4): e030. doi: 10.1097/pq9.0000000000000030. 